\title{
Place, Workplace, and Mindful Movement
}

\begin{tabular}{c|c}
$\begin{array}{c}\text { Sue Erica Smith } \\
\text { Charles Darwin University } \\
\text { sue.smith@cdu.edu.au }\end{array}$ & $\begin{array}{c}\text { Emma Schuberg Barnes } \\
\text { Charles Darwin University } \\
\text { emmaschuberg@gmail.com }\end{array}$ \\
\hline Jon Mason & Julia Broome \\
Charles Darwin University & Feldenkrais Practitioner \\
jon.mason@cdu.edu.au & jbroome7@optusnet.com.au \\
\hline
\end{tabular}

Keywords: mindfulness, embodiment, well-being, teaching, intrapersonal, Feldenkrais, Mindfulness Based Stress Reduction (MBSR)

\begin{abstract}
This paper explores how mindfulness exercises and body awareness can support teacher wellbeing. Combining narrative inquiry and participatory action research this paper documents perspectives of participants and researchers involved in trialling mindfulness in movement practices for teachers in the Northern Territory in Australia. These practices were introduced as part of a pilot study focused on teacher well-being and in response to what we perceived to be the lack of attention given to intrapersonal development in well-being matrices. Through these cycles of workshops and inquiries, we came to learn embodied awareness practice that is situated within a sense of place became an important support for teacher resilience. Although nearly one hundred teachers have participated in these programs, we draw upon the narratives told by one early career teacher as an exemplar of how these practices might play out in the workplace. The auto-ethnographic accounts that intersperse this paper offer insight into the visceral tensions embodied in re-location, location, and the complex (and at times) alarming challenges faced by a beginning teacher in a middle school. Here knowledge, skills and embodied learning must be marshalled and enacted amid the dynamics of what is self-described here as the contact zone of the classroom. These personal narratives of lived experience provide insights into how this form of intrapersonal learning can have benefit for teacher well-being. The paper concludes by raising questions that might direct the profession to formally pursue applications of mindfulness in school well-being agendas.
\end{abstract}

\section{Introduction}

Teachers are busy people in what has long been known to be a stressful profession (Kyriacou \& Sutcliffe, 1978; Borg \& Riding, 1991) and it is a profession that is also prey to the more serious condition of burnout (Hakanen, et al., 2006; Farber, 1984, 1991, 2000; Maslach, et al., 1996; Shaufeli \& Bunk, 2003;Schaufeli, et al., 2002). Yet paradoxically, at a time when student well-being has come to the fore with Social and Emotional Learning (SEL) embedded into the General Capabilities of the Australian Curriculum (ACARA, 2013), and the prevalence of ancillary well-being packages (such as KidsMatter, MindMatters, beyondblue and Response Ability), professional development that supports teachers' well-being and resilience (and their 
facility to bring these qualities into their teaching) is adopted ad hoc in schools, and within these the emphases are primarily on interpersonal communications. Intrapersonal learning is overlooked, often considered to be 'private'. We argue here that intrapersonal awareness is pivotal to both the successes of these student well-being programs and directives, and is intrinsic to teachers' well-being. Mindfulness exercises have provided a technology to bring this domain of learning to the fore with increasing uptake in the secular domains of work (Dane \& Brummel, 2013; Aikens et al., 2014; Van Gordon et al., 2014), psychotherapy (Surrey, 2005; Shapiro \& Carlson, 2009; Germer et al., 2013), and self-development (Brown \& Ryan, 2003; Segall, 2005; Rasmussen \& Pidgeon, 2011). This paper reports on activities that were part of a broader research project in which we sought to explore how these intrapersonal exercises might be employed with teachers to support their well-being and resilience.

\section{Broadening applications of Mindful Inquiry}

As indicated there is a significant and growing body of literature either associated directly with mindfulness training or relevant to it. A plethora of books and journal articles situated within the fields of education, management, neuroscience, psychology, philosophy, and the health sciences broadly speaking (Ager et al., 2014; Burrows, 2013; Clark et al., 2015; Frank et al., 2013; Hassed \& Chambers, 2014; Jennings, 2015; Kabat-Zinn, 2005; Macdonald \& Shirley, 2009; Russell \& Tatton-Ramos, 2014; Shoval, 2011; Webster-Wright, 2013). It is pertinent here that much of this literature is having an impact within the schooling sector and mindfulness training is gaining legitimacy as a practice for both teachers and students (Ager et al., 2014; Hassed \& Chambers, 2014; Jennings, 2015).

Recent research focused on mind-body disorders (Clark, et al., 2015) provides evidence suggesting there is "an important axis of variation for well-being, in which skillful cognitive control covaries with a capacity for skilful movement" (p. 1). In elaborating on this claim, evidence is presented both from mind-body disorder as well as optimized mind-body functioning that can be facilitated by physically-grounded mind training through Feldenkrais techniques (Feldenkrais, 1964; 1981; 1984). The process of exploring experience of movement using a Feldenkrais approach, provides a basis for mindful attention and also facilitates improvement in mind-body functioning.

The value of Feldenkrais Awareness through Movement has been investigated in other domains including leadership and management. In these movement explorations, the student learns how to find ease in moving in many different ways and in this process learns multiple things simultaneously. At a level of tacit learning, $s$ /he recognises the value in generating situations that foster discovery, rather than seeking the "correct" answer, creating a possibility for new learning or a felt understanding to emerge (Goldman-Schuyler, 2010).

The four authors in this paper bring together various perspectives; those of teacher educators, a physiotherapist and Feldenkrais specialist, and an early career teacher. For the academics and the health professional, there is a shared background in meditative practice that spans many decades. During this time, we have watched with interest how mindfulness training we learned and experienced through an interest in Buddhism has entered, it seems, the public imaginary. At times, however, this mainstreaming has also been the cause of some consternation because over exposure and misplaced hype has somehow dislocated the term. The origins of mindfulness are attributed to the Buddha in the Satipatthana Sutta. Traditionally it is taught systematically: mindfulness of body, of feelings, of thoughts and of mind. Mindful awareness becomes the foundation for the cultivation of wisdom, and hence, as affect and effect draws sharpened attention, so too do the ethical implications of body/mind activity draw increasing awareness. Secular and beginning mindfulness practices cultivate calmness, focused attention 
and present awareness that disrupt propensities for (negative) judgmental thoughts. These are healthy outcomes, and needed too. Yet from our perspectives, the scope was potentially diminished without grounding in a yoga (body/mind) tradition and an ethical framework that requires critical engagement and mindful activity based on interconnections, interdependence, and where loving kindness to self and to others is both natural and logical. Nevertheless, while secular mindfulness training does not directly embrace ethical frameworks as Siegel (2007) has reminded us, there is evidence to suggest this type of intrapersonal engagement supports changes in the brain that facilitate improvement in quality of interpersonal engagement.

Over the past three years the two of us engaged in teacher education have pursued a research agenda that connects mindfulness, well-being, and teachers' professional learning. These can be fuzzy constructs but for the purposes of this paper well-being is defined as "when individuals have the psychological, social and physical resources they need to meet a particular psychological, social and/or physical challenge. When individuals have more challenges than resources, the see-saw dips, along with their wellbeing, and vice-versa" (Dodge et al., 2012, p. 230). This dynamic construct is akin to resilience. Mindfulness definitions, too, have many permutations but in essence these exercises engage purposeful non-judgmental, present attention (Kabat-Zinn, 2009). As we explain later in this paper, attention to teachers' wellbeing, and the use of mindfulness exercises, have a legitimate place in teacher professional development programs.

In cycles of teacher professional development, and reflective participatory action research, we have sought to adapt our programs to the stated needs of our participants. From data gathered from our initial workshop it was clear locality, our remote tropical Australian locality in particular, provided both positive and negative impacts on teacher well-being, and the construct of 'place' was incorporated into our programs. As our programs evolved, the timepoor participant teachers requested mindfulness techniques that could be employed amid the dynamics of teaching a lesson. Our inquiry moved to include embodied mindfulness that drew upon the nuanced body learning in Feldenkrais lessons. An early career art teacher, with mythopoetic flourish, adds her auto-ethnographic account to the processes and discussions within this paper.

\section{Participatory action research}

Prior to the commencement of the project, we were granted university ethics approval to pursue the teacher well-being study with teachers in the Northern Territory, Australia. Permission was also granted by the Department of Education to conduct focus groups with teachers and to advertise a weekend symposium through their communications networks. This work aligned with a national focus on the competency and professional learning as determined by the Australian Professional Standards for Teachers (AITSL, 2012). Among others these standards outline teachers are required to Engage in professional learning to improve practice (Standard 6.2) and Engage with colleagues to improve practice (Standard 6.3) to which we have argued that interpersonal and intrapersonal well-being and resilience (aligning with the SEL domains) can be linked to professional development and programs that service this agenda. A senior education department official conceded that providing for teacher well-being falls within the ambit of duty of care.

The teacher focus group interviews that were conducted in three schools, indicated an urgent need to build well-being into professional learning. In response, we hosted 70 participants to a Personal Resilience and Positive Connections weekend seminar and workshop at our university in Darwin. The teachers were animated by the opportunity to connect with each other and share strategies and grumbles. Intrapersonal well-being was introduced through 
mindfulness exercises focused on maintaining attention and presence: non-judgmental awareness of breath, of body, of walking, and when eating. For most of the attendees, mindful walking provided the readiest entry into the practice. Teachers explained in their professional lives, movement was part of their job, and the shift to silence and the seemingly oft-times lack of proficiency that mindfulness invites was disconcerting for some. Thus, while the cultivation of stillness is commonly associated with meditation practice, focusing upon mindfulness in movement appeared to align better with teacher daily routines.

Mindfulness is a meditation technique, and while there are countless meditation techniques that explore the intrapersonal domain, they can generally be classified into three kinds of mental exercise or discipline: mindfulness using attention; imagery using intention; and, reflective contemplation using inquiry (Gawler \& Bedson, 2011). Such a classification does not preclude a combination of techniques and contemporary interventions in educational settings. Hassed \& Chambers (2014), for example, demonstrate the benefits to learning and performance through combining mindful inquiry and attention training through a wide variety of techniques. Mindfulness practices taught to teachers and students include mindfulness of the body through cultivating stillness and mindfulness using simple movements or yoga postures (Meiklejohn et al., 2012). A well-recognised mindful movement practice in a Buddhist framework is walking meditation (Hanh, 1985; Prakhinkit et al., 2014), a practice used for development of concentration that also helps to bring mindfulness practice into daily, embodied activity.

Research studies have shown that heightened awareness of body states enhances both intrapersonal and interpersonal attunement (Siegal, 2007; 2008; 2009; Teper, et al., 2013), which in turn can impact on well-being. An individual's awareness of another person's state of mind depends on how well one knows one's own state. In the brain, messages from systems below the cortex such as heart rate, breathing and muscle tension, the limbic system's colouring of emotion, are sent to inform the cortex of the state of mind. This is the reason, from a brain perspective, that people who are more aware of their bodies are also more empathic. When one can sense his/her own internal state, a pathway opens to resonate with others. Mirror neurones in the brain provide the facility to sense behavioural intentions and emotions of others. The better one can sense one's own bodily sensations, the better the ability to resonate with another yet remain differentiated; important for maintaining a sense of objectivity (Siegel, 2009).

As our participants repeatedly indicated, finding time within the daily routine at school to pause, consider, and perhaps nurture one's own well-being can be challenging and just an added stressor in the workplace. It is also the case that for us - as researchers and practitioners navigating various pathways in our respective careers - making the time for such activity is not easy as it often demands effort and discipline. Creating the conditions for reflection upon one's well-being in the workplace can almost seem counter-intuitive - occupying one's mind with yet another mind-based activity does not seem like 'time out'. Rather, the teachers we engaged with were interested in techniques that could be employed on the move, in the classroom, and in response we looked to kinesthetic approaches.

Following the initial weekend seminar and workshop we offered a Mindful Movement workshop that combined Feldenkrais body awareness exercises and mindfulness practice. The outwardly imperceptible, nuanced movements and curious attention towards these that this method affords, posed a viable route to bring mindful attention into the embodied workplace. Over the next year, we delivered afterschool mindfulness and movement workshops to teachers at two schools, and to some 100 teachers in total. Teachers were keen to introduce mindfulness practices into their classes, but as Jennings (2015) and Hassed \& Chambers (2014) have cautioned, and we too from our personal experiences concur, teachers themselves need to 
personally gain experience in the practice to ably guide their students. At one school, a core group of teachers who completed an eight-week cycle of workshops began to introduce 'mindfulness moments' into their classes.

In this paper the voice of one early career teacher / higher degree candidate who elected to embark on this mindfulness journey provided prose that attempts to both capture the situated and nuanced intrapersonal and embodied focus of our study as (mythopoetically diarised) lived experience in place and body. Throughout our conversations with many teachers the impacts on our well-being by virtue of our remote - and very remote - location in the Northern Territory of Australia became apparent. For, as Power \& Bennet (2015) had reminded us, the idea of place has an established significance in Australian social research.

The narrative prose included below hearkens to Mobeley (2011) who iterates the central role of reflection, enhanced through mindfulness in-service learning - a potent antidote to mindless pre/judgments - and is heartened by Shann (2015, p.128) who positions mythopoetic story writing as means for affective engagement with research.

Our bid for affective reader engagement within this research is a bid to engage further with a beginning teacher's experience and how embodied mindfulness becomes a means for reinhabiting self by returning to senses and a sense of being alive (Gruenwald, 2006). The opening narrative borrows from Sommerville's (2012) framework of place: where stories create relational bonds to place, where the body is central to the experience of place, and crucial to the narrative to follow, where the learning site becomes a 'contact zone' of contested stories. The raw, reflexive and mindful narrative gives play to how too the natural environment directly influences the deep natural world of the psyche within (Tacey, 1995). The time of teaching is also a time of personal learning that is invariably replete with rapid bodily sensations and cat's cradles of thoughts that moved Ellsworth (2005) to ask, "What is it then, to sense one's self in the midst of learning as experience, in the moment of learning, in the presence of a coming of a knowing, in this interleaving of cognition and sensation/movement?" (p. 136). Mindfulness becomes a technology whereby these questions of existential importance might begin to find resolution that is located in body and in place, and even in the classroom workplace.

\section{The teacher connects}

We packed up and shipped out from the south, leaving behind the weight of memory, place and obligation, to push into an unknown land. The beating aorta of this country in winter, throbbing beauty, led us northward. We relocated ourselves in this new territory, to breathe in the red dust, shake it off in hot springs, and dream in a stunning sunset sky full of possibilities. A deep sense of place overcame us.

When we arrived at the edge of the continent, we were greeted by shimmering ochre and cadmium sands. Tantalising cobalt waters beckoned to us, but we were driven back by seen and unseen predators: massive crocs, sharks, box-jellyfish, the invisible irukandji and midges. Relentless heat and humidity ripen perfect conditions for things that gnaw and bite. Conditions cultivate cold-blooded and other heartless creatures: sandflies, fish with big teeth. Other locals with teeth and determination prevail - survivors of Japanese bombardment, 1974's 'Tracy' (the devastating cyclone), corporate cowboys and middle-school students. 
Resilience and cunning are pre-requisites to defy and outlast this place and its ecologies: the weather is its own prevailing intransigent and untamed wild-thing entity; time itself seems to have sung a dreaming lullaby that causes curious slippages here - an ancient traction pervades. Modernity as a frontier sits uncomfortably and belligerently in this landscape.

This defiant, porous frontier presents intriguing daily contradictions and border collisions of place, people and purpose. Cultures and mindsets clash: the ancient and original inhabitants; the well-established south east Asian influence; brash bogan bureaucrats; transient intelligentsia; fickle Fly-In-Fly-Outers; and remnants of the hippy generation who were lured here decades ago and have become the 'keepers of the last of the wild things'... Not to forget the mocking local newspaper, representing the last bastion of the sheer bloody-minded and 'gone-troppo' Aussie yarn-spinner before they step off the shore into the Arafura, slipping into the warming currents to Bali and beyond.

This somewhat motley civilisation is built on the back of a floating economy: exchange is made for precious resources being shipped offshore by foreign barons. There are many uncomfortable costs to determined western presence in this Asia-fringed region. The US military base and annual international 'war-games' attempt to fill the skies and seas to conjure mirages of ironic 'stability'. In a strange twist of symmetry, I was to have my own 'stability' and sense of place challenged, physically, professionally and personally.

\section{The teacher educators reflect}

\section{Place, Body-Consciousness and Stress Reduction}

We also considered how the 'place' of online connectivity might help in developing an ongoing conversation about managing stress through mindfulness. But in our early attempts at doing this we discovered very quickly that time-poor teachers did not wish to engage this way when exploring strategies that might nurture their well-being and preferred an actual time-out option of a physically located workshop or class; engaging online somehow represented continuity of workplace and its associated stressors rather than a retreat from it.

In addressing the problem of managing stress arising from a contemporary culture that chronically fragments our attention through overstimulation, Shusterman (2008) presents "body consciousness" as a "philosophy of mindfulness and somaesthetics" that provides a proven pathway to stress reduction, improved performance, and personal insight (pp. $x$-xii). For Shusterman, somatic philosophy and the body-mind disciplines such as the Alexander Technique and Feldenkrais provide ways in which to observe and break habits that might be detrimental to well-being.

While not focused on the somatic connection, the literature on mindfulness based stress reduction (MBSR) likewise reports mindfulness training can be a successful intervention in ameliorating the effects of anxiety, depression, and stress in the workplace (Flook et al., 2013; Gold et al., 2010). 


\section{The Feldenkrais practitioner explains}

Moshe Feldenkrais, an engineer and physicist, whose keen interest in martial arts and sports underpinned his passion for understanding human movement and learning, The Feldenkrais Method that he developed drew from all of these experiences. His interest heightened following his experience of personal injury. Through a commitment to initially finding a way to improve his movability, and subsequently the ability of others, he developed an intrapersonal inquirybased approach to learning and improving performance. He worked extensively with adults and children with neurological and developmental disabilities, and those with complex and chronic problems. Neuropsychiatrist Norman Doidge considered Feldenkrais to be one of the first neuroplasticians (Doidge, 2015) by his use of attention and non-habitual movement patterns to engage the brain's innate capacity to change habitual patterns and initiate more efficient movement that is attuned to the situated environment. Feldenkrais lessons facilitate change in neuro-muscular organisation; movement becomes more evenly distributed throughout the body so no one part of the system is over-burdened and from this change a feeling of ease can develop.

A number of movement traditions also engage attention and awareness in meditative movements, such as T'ai Chi and yoga. What distinguishes the Feldenkrais Method from other movement paradigms is that it is designed to interrupt movement habits and facilitate the discovery of new ways of carrying out various functions. It does not involve learning a specific sequence or moving to achieve a particular goal, rather the intention is to evoke new learning through attending to the process, moving slowly, doing less and thereby increasing sensitivity and ability to make finer distinctions, with resultant improved ability to sense details of the self and one's surroundings. The person becomes more aware of what they are doing, not what they think they are doing (Beringer, 2010). That, as such, is mindful activity.

He saw the mind and body as a unified functional and biological system, a system that has four aspects: thinking, feeling, sensing and moving.

... [and] that the unity of mind and body is an objective reality. They are not just parts related to each other, but an inseparable whole while functioning. A brain without a body could not think... the muscles themselves are part and parcel of our higher functions. (Feldenkrais, 1964, p. xi)

And

We have no sensation of the inner workings of the central nervous system. We can feel their manifestations only as far as the eye, the vocal apparatus, the facial mobilisation, and the rest of the body provoke our awareness. This is the state of consciousness! (p. 29)

\section{The teacher embarks on embodied mindfulness training}

\section{Feldenkrais - Training, Placefulness}

This challenge to stability has a prequel. I found myself within a week connecting in a different way to place through Feldenkrais training. It became a serendipitous re-positioning, offering embodied mindfulness practice that not only connected me with place but became a crucial resource to draw on during the classroom territory I was to step into. Taking part in a one-day workshop on short mindfulness 
meditations and gentle movement, I found myself lying prone, feeling the ground beneath me, asking: how was my body connecting to this place? What was my mind/body aware of? My lungs filling up like billows, the ribcage expands to embrace the breath and expel tension. Attention to the breath, attention to posture and position and presence, these were the things that echoed back to me often while anticipating the classroom.

The linking of mindfulness to Feldenkrais body learning provided a vehicle for the awareness in action that the teachers in this study were seeking. It served to bridge what can become overly cognitive experiences in mindfulness to grounding in body and place. Because, for any moment in time, two relationships are always present in experience - connection with air through breathing, and relationship to gravity, our base of support. These both provide reference points that can be brought to awareness to help re-connection to the present moment and experience the interdependence of body and mind.

Breathing is a movement of the body, of the diaphragm, chest and abdomen, and varies in response to demands of position, task, degree of effort and emotional state. It is directly affected by the withdrawal response, a primitive protective reflex of survival in response to negative events that might threaten. These may lie anywhere on a scale from vague apprehensions, gnawing anxieties to overt dangers. The withdrawal response is a neuromuscular response to stress expressed in tightening of muscles around the eyes and forehead, neck, shoulders and the abdomen. It also effects breathing, either as shallow breathing or held breath (Hanna, 1988).

These patterns can all become unconscious habits over time, as reflected in the body pattern of anxiety. Developing awareness of the breath enables recognition of anxiety responses and provides scope to change this expression of anxiety in the body and breath, with the potential to also change the quality of emotional affect (Kerr et al., 2002; Payne, \& Crane-Godreau, 2015).

Similarly, developing awareness of relationship to the ground when moving, through sensing skeletal support can enable intentional connection to the ground. The process reduces tension and can provide more ease and clarity in movement and greater flexibility in how the individual responds to the environment (Feldenkrais, 1964).

...the point of my work is to lead to awareness in action. Or the ability to make contact with one's own skeleton and muscles and with the environment practically simultaneously... (Feldenkrais, 1964, cited in Beringer, 2010, pp. 36-37)

This training, conducted during the term break, and practiced by our participant prior to school commencing appears to have provided some intrapersonal strategies that put her in good stead. As is the case for many beginning teachers she was, like Chang (2009) had warned, typically underprepared for the "the dramatic range of intense emotions they will experience so they may enter the profession" (p. 212).

\section{The teacher and personal identity explored}

\section{Place - Classroom Contact Zone, Focus on Mindful Breathing}

Then Term Four arrived - I did not anticipate that the classroom would evoke the Contact Zone I experienced as a junior army cadet; I did not anticipate the similarities between the classroom and my cadet experience. 
It's a preparation moment prior to engagement in the Contact Zone. The strategy is reviewed, supplies are distributed, stations are readied. Contact! The class swarms in, fast and furious, and another 'typical' live-action sequence plays out. Midskirmish, at about half past Year 8, I start to feel the onslaught of an internal conflict: the anxiety attack. As I start to be taken up in a wave of panic, everything around me seems to click over into slow-motion. The whirl of the kids and my presence in the classroom dissipates. I focus on my breath. Slow, deep breaths, in order not to fuel the rising tide of that overwhelming wave. I focus on my breath. I tell myself: this will pass. I focus on the breath. I say: this is not a heart attack. I focus on the breath. I think about asking a trustworthy student to go into the next classroom to request a brief visit from the teacher: just in case I pass out and the students jam $2 B$ pencils and pieces of broken eraser up my nose while I'm unconscious. I focus on the breath, and as I am mindfully breathing, the dizzying heart-rate is slowing, I find myself re-surfacing into the rowdy classroom. The anxiety attack is over. Now to engage again back in the Zone...

\section{Feldenkrais - Reprieve, Reflect, Re-pattern}

During term time, I was offered respite from the Contact Zone, a place for awareness. These were mind and movement sessions in a neutral space, that became tactical exercises. The training sessions helped me connect slowly again with the ground beneath me, aware of feet, placement and breathing. It helped me reflect and devise new tactics. The new tactic was a disruption that attempted a re-patterning, whilst anticipating the classroom. The disruption was a trigger for me, and the trigger was drinking water. It reminded me to focus on the breath and bring my awareness back to my body. While I drank water, this trigger helped me ask, what was I embodying? How was my body positioned? What was I mindfully or absentmindedly playing out in classroom contact?

\section{Placeless - Disconnection, Fracture, Re-connect}

While on-leave, in a non-place, I lost my footing. On a steep and slippery slope, in gripless shoes, with hands full, mind elsewhere, body disengaged and placeless, the full impact of the fall was taken by the fibula. Fractured leg and ankle. A trauma surgeon intervenes. Hardware holding me together - internally and parasitically. I am now part-machine, after a life free from broken bones, I cracked and have a steel plate, a dozen screws and large nail as structural truss. Hyper full-of-mind now, every small step is pre-meditated, minutely assessed and over-anticipated. I learn to walk again slowly, into uncertain months and rocky terrain. Feldenkrais and physio try to revive and re-connect patterns between brain, breath and body. With shifting ground beneath me, I return to Darwin... and gradually into the classroom.

\section{Placefulness - Re-adjust, Re-pattern}

As I initially return into the classroom, I am aware of how vulnerable I still am. I realise that the physical and psychological rough and tumble of the middle school is too confronting at this time. I seek other opportunities outside the teaching profession. I contact recruiters, submit applications, attend interviews. But I know 
that even though I can entertain this reality, a change of profession, I have invested much in re-training and creative energy in the education space. I seek wise counsel from seasoned education mentors and professionals, and continue to pursue connections with holistic education philosophies and practice. It is hard to deny that as a teacher, if I am to prevail in uncertain conditions and shifting times, I need to align myself with supportive, placeful, holistic realities in education. If I need to cultivate resilience through connection to place, mind and body awareness and health, what do students need to cultivate in their own virtual, dis-embodied and digitally-obsessed worlds? And how will teachers do this? Intrapersonal learning that develops holistic connections and supports teacher well-being and professional longevity, should be acknowledged within the Australian Professional Standards for Teachers (AITSL, 2012). I am hopeful that embodied mindfulness and thoughtfully constructive professional ways of well-being can address holistic connection to place, healthy mind-body, and learning.

\section{Discussion}

Within the broader literature we also find that di Nucci (2013) offers a playful antidote to the sometimes over exposed or over appropriated usage of the term mindfulness by considering a close antonym - mindlessness:

Thinking is overrated: golfers perform best when distracted and under pressure; firefighters make the right calls without a clue as to why; and you are yourself ill advised to look at your steps as you go down the stairs, or to try and remember your pin number before typing it in. Just do it, mindlessly. ... our mindless self is our true self because it is not mediated by thought. Being mindless is, in short, a good thing. Let us not be ashamed of it; let us cultivate it.

(di Nucci, 2013, p. 10)

Such a position opens a whole other facet to this discussion and is introduced principally because it actually misses the point of mindfulness training. The core concept within di Nucci's notion of mindlessness is really automaticity, an essential transition in learning that frees an activity from conscious control. The brain, particularly in the pre-motor cortex, forms what are called functional body maps, linkages of groups of neurons related to a particular function, e.g., walking, reaching, driving a car etc. As a baby learns through transitions to the upright and mobile state, change in the brain takes place. This creates freedom to either simply be present in the moment, with whatever sensations and thoughts arise, or to allow the conscious mind to engage in other "pastimes". Mindful movement, however, is to do with attunement of mind and body, and places emphasis upon the physicality of mindfulness training.

Teachers too need this type of embodied capacity to move and to act with common sense. It is also informed by efforts at cross-disciplinary thinking. Thus:

At first glance, contemplative mindfulness and critical inquiry seem at opposite poles of a reflective spectrum, yet Eastern and Western philosophers have described a dual dimension to reflective thought that incorporates both. 'Mindful inquiry' offers an holistic re-conceptualisation of reflective thinking, which holds mindfulness and inquiry in a dialectic inter-relationship

(Webster-Wright, 2013, p. 557). 
Similarly, mindfulness training and mindful inquiry open ethical imperatives. As seen throughout the narrative, calm and focused non-judgemental attention provides pause for active choice rather than reactive response, highlighting that behavior is closely linked with optimized intrapersonal functioning. Ethical practice in teaching, however, is currently only conceived in terms of professional responsibility (AITSL, 2012).

Both the mindful inquiry and embodied learning that have been introduced here to teachers represent ways of learning where tools to develop awareness of the unity of body and mind are learned and practised, and in some cases, such as in the prose presented here, a deeper sense of learning is experienced. Many teachers are stressed, burning out and vulnerable, and this can be especially so for teachers beginning their careers - yet, how are the relevant authorities dealing with this? Initially we took a liberal interpretation of the current professional standards by seeking to address teacher well-being, and the intrapersonal, as an ever-present domain that has an impact upon performance. Arguably, it is through a critical reading of the professional standards that neglect of the intrapersonal can be seen as an abrogation of professional responsibility.

Each participant in our study has his or her own personal narrative and unique situated experience, but as the beginning teacher featured in this paper concluded in an interview following the workshop, "The supports and technologies that were made available presented a different way of learning and filled a need for deeper fulfillment, beyond Professional Standards, towards authentic being". Such a comment alludes to bigger issues concerning the scope and outcomes of teacher professional development because the current (2012) version of the AITSL Professional Standards for Teachers is framed around competencies rather than capacity and performance. Thus, while effective teaching and learning performance is explicit in the standards, the intrapersonal domain of teachers is not flagged as a topic of professional learning.

Addressing the intrapersonal is perhaps an ambitious form of learning in a time-strapped, outcome-and-performance-based environment and while there has been a meteoric rise in secular mindfulness training the wider and longer term implications of body, emotion, ethics and regular practice might mean we are seeing an exotic shower before the burn. Indications from our research, however, are otherwise and point to the need for sustained advocacy to establish teacher well-being professional development programs that include intrapersonal learning is warranted and legitimate facet of professional as well as personal wellbeing.

The existing problems for teachers, and in turn students, represent what Feldenkrais described as a vast field in mind-body relationship yet to be explored. As he explained:

There can be no improvement without change. Though help can be given when things go wrong, we cannot relax our effort before teachers throughout the world will learn to develop in their students awareness of the unity of body and mind so that higher achievements than merely correcting faults can be arrived at. Training a body to perfect all the possible forms and configurations of its members changes not only the strength and flexibility of the skeleton and muscles, but also makes a profound and beneficial change in the self-image and the quality of direction of the self (Feldenkrais, 1964, cited in Beringer, 2010, pp. 43 - 44).

This approach is a potentially rich field for further inquiry, and a useful start to changing behaviour. The voices in this paper all tell stories while combining to present a common and coherent picture that has identified needs and links to strategies to meet them. 
It is also relevant that within the growing discourse on $21^{\text {st }}$ century skills (or competencies), given the range of conceptualisations, there is arguably a natural fit for mindfulness training. Thus, educational theorists such as Gardner (2011), has identified the "disciplined mind" and the "ethical mind" as two of "five minds for the future" needing attention and development within educational settings. Mindfulness practice serves both of these directions.

\section{Questions Arising and Conclusion}

As we bring this discussion to a close, we find a number of questions emerge from these interrelated narratives that will be important for us to probe deeper as we continue to scope the implications of our research agenda connecting mindfulness training with teacher professional learning. Indeed, it has been our purpose to identify such questions rather than to reach 'conclusions' that bring closure to the issues raised. Thus, the following questions point to the need for continued investigation into the issues addressed in this paper:

1. What are the relevant authorities doing to address issues of teacher well-being and teacher burnout?

2. Does mindfulness training and intrapersonal development properly sit within teacher professional learning requirements? If so, then how can it best be situated and promoted?

3. What movement-based awareness practices might be most suited to adoption in schools?

4. In what ways might 'place' and 'placelessness' be further explored as considerations for intrapersonal well-being?

5. In what ways could policy development concerned with teacher professional practice bring into better alignment the well-being, learning, performance, and competencies of teachers?

In conclusion, a number of key issues remain prominent for educational authorities to consider. Well-being is a rich and complex topic to explore given that it is experiential, highly nuanced, and sometimes a personal and private matter. By illustrating this through an auto-ethnography of a pre-service teacher, we have come to the view that further research into teacher wellbeing is both warranted and timely. Secondly, we think a critical reading of the professional standards for teachers reveals neglect of the intrapersonal domain. As such, this omission can be interpreted as an abrogation of professional responsibility. 


\section{References}

Ager, K., Bucu, A., Albrecht, N., \& Cohen, M. (2014). Mindfulness in Schools Research Project: Exploring Teachers' and Students' Perspectives - Preliminary Report. Melbourne: RMIT University.

Aikens, K.A., Astin, J., Pelletier, K.R., Levanovich, K., Baase, C.M., Park, Y.Y., \& Bodnar, C.M. (2014). Mindfulness goes to work: Impact of an online workplace intervention. Journal of Occupational and Environmental Medicine, 56(7), 721-731.

Australian Curriculum Assessment and Reporting Authority (ACARA). (2013).

Australian Institute for Teaching and School Leadership (AITSL). (2011). National professional standards for teachers. Retrieved 20/02/2016, from http://www.aitsl.edu.au/Beringer, E. (Ed.) (2010). Embodied Wisdom: The Collected papers of Moshe Feldenkrais. San Diego, CA: Somatic Resources.

Borg, M.G., \& Riding, R.J. (1991). Occupational stress and satisfaction in teaching. British Educational Research Journal, 17, 263-281.

Brown, K.W., \& Ryan, R.M. (2003). The benefits of being present: mindfulness and its role in psychological well-being. Journal of personality and social psychology, 84(4), 822.

Burrows, L. (2013). Transforming "The Red Beast” Within Through Mindfulness and Therapeutic Storytelling: A Case Study. Australian Journal of Guidance and Counselling, 23(2), 172-184. doi: 10.1017/jgc.2013.17

Clark, D., Schumann, F., \& Mostofsky, S. (2015). Mindful movement and skilled attention. Frontiers in Human Neuroscience: Hypothesis and Theory, 9(297), 1-23. doi: 10.3389/fnhum.2015.00297

Chang, M.L. (2009). An appraisal perspective of teacher burnout: Examining the emotional work of teachers. Educational psychology review, 21(3), 193-218.

Dane, E., \& Brummel, B.J. (2013). Examining workplace mindfulness and its relations to job performance and turnover intention. Human Relations, 67(1), 105-128. doi: 10.1177/0018726713487753.

Di Nucci, E. (2013). Mindlessness. Newcastle upon Tyne, UK: Cambridge Scholars.

Dodge, R., Daly, A., Huyton, J., \& Sanders, L. (2012). The challenge of defining wellbeing .International Journal of Wellbeing, 2(3), 222- 235. doi: 10.5502/ijw.v2i3.4

Doidge, N. (2015). The Brain's way of Healing: Remarkable Discoveries and Recoveries from the Frontiers of Neuroplasticity. Brunswick, Vic: Scribe Publications.

Ellsworth, E. (2005). Places of learning: Media, architecture, pedagogy. New York, NY: Routledge.

Farber, B.A. (1984). Stress and burnout in suburban teachers. Journal of Educational Research, 77, 325-331

Farber, B.A. (1991). Crisis in education: Stress and burnout in the American teacher. San Francisco. Jossey-Bass.

Farber, B.A. (2000). Treatment strategies for different types of teacher burnout. Journal of Clinical Psychology, 5, 675-689.

Feldenkrais, M. (1964). Mind and Body. Systematics: The Journal of The Institute for the Comparative Study of History, Philosophy and the Sciences, 2(1).

Feldenkrais, M. (1981). The Elusive Obvious. Cupertino, California: Meta Publications.

Feldenkrais, M. (1984). The Master Moves. Cupertino, California: Meta Publications. 
Flook, L., Goldberg, S., Pinger, L., Bonus, K., \& Davidson, R. (2013). Mindfulness for Teachers: A Pilot Study to Assess Effects on Stress, Burnout, and Teaching Efficacy. Mind, Brain, and Education, 7(3), 182-195.

Frank, J., Jennings, P., \& Greenberg, M. (2013). Mindfulness-Based Interventions in School Settings: An Introduction to the Special Issue. Research in Human Development, 10(3), 205-210. doi: 10.1080/15427609.2013.818480.

Gardner, H. (2011). Five Minds for the Future. In J. Bellanca \& R. Brandt (Eds.), $21^{\text {st }}$ Century Skills: Rethinking How Students Learn (pp. 9-30). Bloomington, IN: Solution Tree Press.

Gawler, I., \& Bedson, P. (2011). Meditation: An in-depth Guide. Melbourne: Penguin.

Germer, C.K., Siegel, R.D., \& Fulton, P.R. (Eds.). (2013). Mindfulness and psychotherapy. New York, NY: The Guilford Press.

Gold, E., Smith, A., Hopper, I., Herne, D., Tansey, G., \& Hulland, C. (2010). Mindfulness-Based Stress Reduction (MBSR) for Primary School Teachers. Journal of Child and Family Studies, 19, 184189. doi: 10.1007/s10826-009-9344-0.

Goldman-Schuyler, K. (2010). Consulting Psychology Journal: Practice and Research, 62(1), 21-38.

Gruenewald, D. (2006). Resistance, reinhabitation, and regime change. Journal of Research in Rural Education, 21(9), 1-7. Retrieved from http://jrre.vmhost.psu.edu/wp-content/ uploads/2014/02/21-9.pdf.

Hakanen, J., Bakker, A., \& Schaufeli, W. (2006). Burnout and work engagement among teachers. Journal of School Psychology, 43(6), 495-513. doi: 10.1016/j.jsp.2005.11.001.

Hanh, T.N. (1985). Guide to Walking Meditation. Fellowship Publications

Hanh, T.N., \& Vriezen, W. (2008). Mindful Movements: Ten Exercises for Well-Being. Berkeley, CA: Parralax Press.

Hanna, T. (1988). Somatics: Reawakening The Mind's Control of Movement, Flexibility, and Health. Cambridge, MA: Perseus Books.

Hassed, C., \& Chambers, R. (2014). Mindful Learning. Wollombi, NSW: Exisle Publishing.

Jennings, P. (2015). Mindfulness for Teachers: Simple Skills for Peace and Productivity in the Classroom. New York, NY: W.W. Norton \& Company.

Kabat-Zinn, J. (2005). Coming to our senses: healing ourselves and the world through mindfulness. New York: Hyperion.

Kabat-Zinn, J. (2009). Wherever you go, there you are: Mindfulness meditation in everyday life. UK: Hachette.

Kerr, G.A., Kotynia, F., \& Kolt, G.S. (2002). Feldenkrais ${ }^{\circledR}$ awareness through movement and state anxiety. Journal of Bodywork and Movement Therapies, 6(2), 102-107.

Kyriacou, C., \& Sutcliffe, J. (1978). A model of teacher stress. Educational studies, 4(1), 1-6.

Macdonald, E., \& Shirley, D. (2009). The Mindful Teacher. New York, NY: Teachers College, Columbia University.

Maslach, C., Jackson, S.E., \& Leiter, M.P. (1996). Maslach burnout inventory manual (3 ${ }^{\text {rd }}$ edition). PaloAlto Consulting Psychologists Press.

Meiklejohn, J., Phillips, C., Freedman, M.L., Griffin, M.L., Biegel, G., Roach, A., \& Isberg, R. (2012). Integrating mindfulness training into $\mathrm{K}-12$ education: Fostering the resilience of teachers and students. Mindfulness, 3(4), 291-307. 
Mobeley, C. (2011). Diversity and service-learning. In T. Stewart \& N. Webster (Eds.), Exploring cultural dynamics and tensions within service-learning. Charlottte, NC: Information Age Publishing.

Napoli, M. (2004). Mindfulness Training for Teachers: A Pilot Program. Journal of Evidence-Based Complementary and Alternative Medicine, 9(1), 31-42. doi: 10.1177/1076167503253435.

Power, A., \& Bennet, D. (2015). Moments of becoming: experiences of embodied connection to place in arts-based service learning in Australia. Asia-Pacific Journal of Teacher Education, 43(2), 156-168. doi: 10.1080/1359866X.2014.960801.

Prakhinkit, S., Suppapitiporn, S., Tanaka, H., \& Suksom, D. (2014). Effects of Buddhism walking meditation on depression, functional fitness, and endothelium-dependent vasodilation in depressed elderly. The Journal of Alternative and Complementary Medicine, 20(5), 411-416.

Payne, P., \& Crane-Godreau, M.A. (2015). Meditative movement for depression and anxiety. Progress in Physical activity and Exercise and Affective and Anxiety Disorders: Translational Studies, Perspectives and Future Directions, 4(71), 50-64. doi: 10.3389/fpsyt.2013.00071.

Rasmussen, M.K., \& Pidgeon, A.M. (2011). The direct and indirect benefits of dispositional mindfulness on self-esteem and social anxiety. Anxiety, Stress, \& Coping, 24(2), 227-233.

Russell, T., \& Tatton-Ramos, T. (2014). Body In Mind Training: Mindful Movement for the Clinical Setting. Neuro-Disability \& Psychotherapy, 2(1-2), 108-136.

Schaufeli, W., \& Bunk, B. P. (2003). Burnout: An overview of 25 years of research and theorizing. In M.J. Schabracq, J.A.M. Winnubst, \& C.L. Cooper (Eds.), Handbook of work and health psychology (pp. 383-425). Chichester: John Wiley \& Sons.

Schaufeli, W., Salanova, V., González-Roma, A.B., \& Bakker, A. (2002). The measurement of engagement and burnout: A two sample confirmatory factor analytic approach. The Journal of Happiness Studies, 3, 71-92.

Shann, S. (2015), A mythopoetic methodology: storytelling as an act of scholarship. Asia-Pacific Journal of Teacher Education, 43(2), 128-142. doi: 10.1080/1359866.2014.932334.

Shapiro, S.L., \& Carlson, L.E. (2009). The art and science of mindfulness: Integrating mindfulness into psychology and the helping professions. Washington, DC: American Psychological Association.

Segall, S.R. (2005). Mindfulness and self-development in psychotherapy. Journal of Transpersonal Psychology, 37(2), 143.

Shoval, E. (2011). Using mindful movement in cooperative learning while learning about angles. Instructional Science, 39(4), 453-466. doi: 10.1007/s11251-010-9137-2.

Shusterman, R. (2008). Body Consciousness: A Philosophy of Mindfulness and Somaesthetics. New York, NY: Cambridge University Press.

Siegel, D.J. (2007). The Mindful Brain: Reflection \& Attunement in the Cultivation of Well-Being. New York, NY: WW Norton \& Company Inc.

Siegel, D.J. (2008). The Mindful Brain: The Neurobiology of Well-being. Sounds True.

Siegel, D.J. (2009). Mindsight: Change Your Brain, Change Your Life. Brunswick, Vic: Scribe Publications.

Sommerville, M. (2012). Water in a dry land: Place learning through art and story. New York, NY: Routledge.

Surrey, J.L. (2005). Relational psychotherapy, relational mindfulness. Mindfulness and psychotherapy, $91-110$. 
Tacey, D. (1995). Edge of the sacred. Melbourne, Harper Collins.

Teper, R., Segal, Z.V., \& Inzlicht, M. (2013). Inside the mindful mind how mindfulness enhances emotion regulation through improvements in executive control. Current Directions in Psychological Science, 22(6), 449-454.

Van Gordon, W., Shonin, E., Zangeneh, M., \& Griffiths, M.D. (2014). Work-related mental health and job performance: can mindfulness help? International Journal of Mental Health and Addiction, 12(2), 129-137.

Webster-Wright, A. (2013). The eye of the storm: a mindful inquiry into reflective practices in higher education. Reflective Practice: International and Multidisciplinary Perspectives, 14(4), 556-567. doi: 10.1080/14623943.2013.810618. 